Thiago Ingrassia Pereira

\title{
ENSINO DE SOCIOLOGIA E EDUCAÇÃO POPULAR: PROBLEMATIZANDO A ESCOLA PÚBLICA
}

\section{TEACHING OF SICIOLOGY AND POPULAR EDUCATION: PROBLEMATIZING PUBLIC SCHOOL}

\author{
Thiago Ingrassia Pereira ${ }^{1}$
}

\section{RESUMO}

A disciplina de sociologia torna-se obrigatória no Brasil a partir de Lei Federal em 2008, porém sua legitimidade na educação básica e, em especial, no ensino médio permanece um campo em disputa, mobilizando a comunidade científica politicamente engajada no debate sobre a qualificação do espaço curricular da área de ciências sociais na escola. A introdução da sociologia no ensino médio mostra-se contemporânea da discussão sobre a própria reorganização desse nível de ensino, criando um cenário de insegurança em relação aos processos acadêmico-formativos e profissionais. Assim sendo, disputar o sentido das reformas curriculares em curso pode representar uma oportunidade de tornar visível a contribuição formativa da sociologia, problematizando o seu lugar na escola pública. A sustentação teóricoprática em princípios da educação popular sinaliza para um compromisso político com desdobramentos epistemológicos e metodológicos, reconhecendo a contribuição do pensamento freireano na construção de uma escola pública e popular.

Palavras-chave: Ensino de sociologia. Educação popular. Escola pública.

\section{ABSTRACT}

The sociology classes are mandatory in Brazil according to federal law (2008), however their legitimacy in basic education, especially, in high school, remains a field of dispute, which involves the scientific community politically engaged in the discussions about qualification of curricular area of social science at school. The introduction of sociology in high school shows up a contemporary discussion about the reorganization in this level of education, which causes a scenario of insecurity in relation to the processes of academic formation and professional.Thus, the dispute of direction on the ongoing curricular reform can represent an opportunity to make visible the formative contribution of sociology, problematizing its space in public

\footnotetext{
1 Sociólogo, Doutor em Educação (UFRGS). Professor Adjunto da área de Fundamentos da Educação e do Programa de Pós-Graduação Profissional em Educação e do Programa de PósGraduação Interdisciplinar em Ciências Humanas da Universidade Federal da Fronteira Sul (UFFS), Campus Erechim/RS. Tutor do Grupo PET/Conexões de Saberes Práxis-Licenciaturas (Bolsista FNDE). Vice-presidente da Associação Brasileira de Ensino de Ciências Sociais (ABECS), gestão 2013-2016. E-mail: thiago.ingrassia@uffs.edu.br.
} 
school. The theoretical and practical support in principles of popular education signals a political commitment to epistemological and methodological developments, recognizing the contribution of Freire's thought in the constitution of public and popular school.

Key-words: Teaching of sociology. Popular Education. Public School.

\section{PRIMEIRAS PALAVRAS}

As reflexões que serão apresentadas neste artigo originam-se do meu percurso como professor e pesquisador na área da sociologia escolar. Por isso, fiz a opção pela escrita em primeira pessoa, já que este corresponde a um texto que se forma na minha práxis, ora sendo um testemunho de minhas experiências como docente na educação básica e superior, ora resultado de meu diálogo com a comunidade científica que tem pesquisado a respeito do ensino de sociologia.

Dessa forma, assumo um dos grandes impasses dos intelectuais na contemporaneidade (GARCIA, 2011), questionando-me: para quem pesquiso? Para quem escrevo? De certa forma, compartilho essa angústia com uma parcela de colegas que procura não apenas a inserção nas estruturas produtivistas da universidade, mas também situar-se como sujeito político, assumindo responsabilidades com esse lugar material e simbólico de ser universitário.

Por essa razão, ser produtivo faz parte dessa assunção que nos posiciona como sujeitos que produzem conhecimentos. Escrever não é apenas um mero ato burocrático do meu ofício, mas, sobretudo, uma possibilidade de diálogo com pessoas que, em diferentes tempos e lugares, desenvolvem preocupações como as que vou explicitar aqui. Nas palavras de Paulo Freire, sintetizo meu argumentosentimento inicial:

escrever, para mim, vem sendo tanto um prazer profundamente experimentado quanto um dever irrecusável, uma tarefa política a ser cumprida. A alegria de escrever me toma o tempo todo [...]. Em minha experiência pessoal, escrever, ler e reler as páginas escritas, como também ler textos, ensaios, capítulos de livros que tratam o mesmo tema sobre que estou escrevendo ou temas afins, é um procedimento habitual (FREIRE, 1994, p. 15). 
ENSINO DE SOCIOLOGIA E EDUCAÇÃO POPULAR: PROBLEMATIZANDO A ESCOLA PÚBLICA

Thiago Ingrassia Pereira

Com base nessa compreensão, escrever este artigo me levou a ratificar posições que tenho sobre a relevância do espaço curricular da sociologia, representando a área de ciências sociais (juntamente com a antropologia e a ciência política), assim como a resgatar a importância da escola pública nesse processo permanente de legitimação da sociologia na educação básica.

Para essa tarefa, busquei em minhas vivências e leituras no/do campo da educação popular aportes para apresentar uma argumentação que sustente minha perspectiva sobre as contribuições do ensino de sociologia para a construção da escola pública e popular no Brasil. A reinvenção de Paulo Freire a partir da problemática do ensino de sociologia na educação básica é uma aposta que venho fazendo, pois considero que as potencialidades do ensino de sociologia podem se associar à luta por uma escola emancipatória.

\section{ENSINAR E APRENDER SOCIOLOGIA NA ESCOLA PÚBLICA}

A escola, como tempo e espaço da educação formal, é uma construção humana, portanto, não é algo natural que sempre existiu no horizonte formativo humano. Por essa razão, escolarização e educação não são termos sinônimos, ainda que guardem proximidade. De diferentes formas, podemos compreender que a escola é uma invenção que causou "rupturas" com o saber comunitário. Desse modo,

a produção de um saber popular se dá, pois, em direção oposta àquela que muitos imaginam ser a verdadeira. Não existiu primeiro um saber científico, tecnológico, artístico ou religioso "sábio e erudito" que, levado a escravos, servos, camponeses e pequenos artesãos, tornou-se, empobrecido, um "saber do povo". Houve primeiro um saber de todos que, separado e interdito, tornou-se "saber erudito"; o saber legítimo que pronuncia a verdade e que, por oposição, estabelece como "popular" o saber do consenso de onde se originou. A diferença fundamental entre um e outro não está tanto em graus de qualidade. Está no fato de que um, "erudito", tornou-se uma forma própria, centralizada e legítima de conhecimento associado a diferentes instâncias de poder, enquanto o outro, "popular", restou difuso - não centralizado em uma agência de 
ENSINO DE SOCIOLOGIA E EDUCAÇÃO POPULAR: PROBLEMATIZANDO A ESCOLA PÚBLICA

Thiago Ingrassia Pereira

especialistas ou em um polo separado de poder - no interior da vida subalterna da sociedade (BRANDÃO, 2006, p. 30-31).

Nessa mesma linha, há o entendimento de que a escola se hegemonizou ao longo do século $X X$ como o espaço por excelência da educação. As relações da escola com os aspectos econômicos, políticos e culturais da sociedade ocidental vão demarcar um percurso de progressiva "massificação", buscando atender as necessidades capitalistas em expansão. É interessante refletirmos que

vivemos, hoje, uma situação ao mesmo tempo problemática e paradoxal. O século XX marcou o triunfo decisivo da escolarização, cujo desenvolvimento foi suportado e acompanhado por um conjunto de promessas que têm origem no Século das Luzes e que associam escola, razão e progresso. A realidade, porém, não confirmou as promessas, o que explica que, relativamente à educação escolar, se tenha passado da euforia ao desencanto (CANÁRIO, 2006, p. 11-12).

Em sociedades com alto grau de desigualdade, como o verificado na América Latina, a escola foi inicialmente pensada para poucos. No Brasil, no final do século XIX, estimava-se que aproximadamente $85 \%$ da população era analfabeta (SOUZA, 2008), ao passo que, cem anos depois, praticamente foi universalizado o acesso ao ensino fundamental. De poucos para muitos, a escola ao se massificar acompanhou a própria estrutura verticalizada de nossa sociedade, ou seja, construímos diferentes escolas, atravessadas por questões de classe social, gênero e etnia (raça).

Essa "escola dual", do acolhimento social para os pobres e do conhecimento para os ricos (LIBÂNEO, 2012), contribuiu para reproduzir no âmbito do sistema escolar as clivagens do sistema social, ratificando uma das premissas da tradição reprodutivista em educação, qual seja, as desigualdades sociais se desdobram em desigualdades escolares (BOURDIEU; PASSERON, 2008). Nesse sentido,

na América Latina, nos países cujos modelos políticos e econômicos se pautaram pela ideologia desenvolvimentista, a escola, especialmente a escola pública, teve como um de seus principais objetivos, junto às classes populares, prepará-las para o mundo do trabalho, garantindo uma força de trabalho minimamente educada, além de inculcar e difundir a ideologia liberal de acesso e 
ENSINO DE SOCIOLOGIA E EDUCAÇÃO POPULAR: PROBLEMATIZANDO A ESCOLA PÚBLICA

Thiago Ingrassia Pereira

democratização do conhecimento socialmente produzido para todos (ESTEBAN; TAVARES, 2013, p. 293).

Contudo, a escola, em especial a pública, além dos traços reprodutivistas, sempre apresentou grande potencial transformador. Essa aposta na escola enquanto instituição "viva" está presente no trabalho científico e militante de Florestan Fernandes (1989, 1966), inclusive no investimento que fez na defesa do ensino de sociologia na escola secundária e na campanha pela escola pública.

Nessa linha, na perspectiva freireana, a escola é um lugar especial, um lugar de gente, gente que se relaciona, que sonha, que convive com as contradições da sociedade. Por esse motivo, a luta pela reinvenção da escola e da própria educação é permanente na agenda política de Freire. Para esse autor, "[...] por isso que, ao lado da tarefa reprodutora que tem, indiscutivelmente, a educação, há uma outra, a de contradizer aquela. Aos progressistas é esta a tarefa que nos cabe e não fatalistamente cruzar os braços" (FREIRE, 2003, p. 98).

Resolvi "não cruzar os braços" nesse momento histórico. Tendo me engajado na chamada "campanha da obrigatoriedade do ensino de sociologia" nos anos 2000 , tive experiências (in)tensas de docência na escola. No ano em que foi publicada a Lei n. 11.684/2008, denominada "Lei da obrigatoriedade", estava em sala de aula, trabalhando com as disciplinas de sociologia e filosofia. Curiosamente, minha experiência como professor de sociologia naquele momento acontecia no ensino fundamental na rede pública municipal de São Leopoldo, município da grande Porto Alegre. No ensino médio, trabalhava em uma das mais tradicionais escolas privadas da capital gaúcha.

Essa experiência na educação básica, iniciada já em 2005, portanto, durante o processo que culminou com os posicionamentos ${ }^{2}$ do Conselho Nacional de Educação (CNE) favoráveis à inclusão obrigatória das disciplinas de sociologia e filosofia em 2006, permitiu-me compreender, por meio da prática pedagógica concreta em turmas dos ensinos fundamental e médio, limites e possibilidades da área de ciências sociais no currículo escolar, bem como da própria escola.

\footnotetext{
${ }^{2}$ Parecer da Câmara de Educação Básica (CEB) n. 38/2006 e Resolução n. 4, de 16 de agosto de 2006.
} 
ENSINO DE SOCIOLOGIA E EDUCAÇÃO POPULAR: PROBLEMATIZANDO A ESCOLA PÚBLICA

Thiago Ingrassia Pereira

Ao refletir sobre essa experiência (PEREIRA, 2010), dialoguei com a proposta educacional freireana, apostando em categorias centrais como o diálogo e o pensar certo. Vale destacar que não busquei uma "aplicação" do arcabouço teórico freireano na escola, mas, pelo contrário, a partir dos desafios de minha prática pedagógica é que fui buscar subsídios analíticos em Freire.

Minha leitura de Paulo Freire se iniciou pela Pedagogia da Autonomia (FREIRE, 2005) e o conceito de "do-discência" me pareceu relevante para organizar minha intervenção na área de ciências sociais na escola. Esse autor argumenta que

ensinar, aprender e pesquisar lidam com esses dois momentos do ciclo gnosiológico: o em que se ensina e se aprende o conhecimento já existente e o em que se trabalha a produção do conhecimento ainda não existente. A "do-discência" - docência-discência - e a pesquisa, indicotomizáveis, são assim práticas requeridas por estes momentos do ciclo gnosiológico (FREIRE, 2005, p. 28).

Com base no exposto, entendi a radicalidade, talvez uma "obviedade" para alguns, de que somente podemos ser professores se formos estudantes, ou seja, que somente ensina quem aprende. Por outro lado, a pesquisa e o ensino são momentos distintos e complementares desse ciclo gnosiológico, sugerindo que a formação continuada é uma exigência da atividade docente. Desse modo, cheguei às escolas disposto a lecionar sociologia partindo (jamais ficando) dos "saberes de experiência feitos" dos estudantes.

O currículo escolar, formal, oculto ou real, reflete disputas de poder no âmbito da sociedade, desnaturalizando as funções da escola em determinado contexto histórico. Dessa forma, problematizar as questões curriculares produz condições objetivas de construção de um projeto de escola associado a um projeto de sociedade. Ao buscarmos uma "sociologia dos saberes escolares" (VALLE, 2014), podemos ter elementos para compreender as contradições da escola e ensaiarmos alternativas de enfrentamento dos processos burocratizantes e inibidores da autonomia dos sujeitos discentes e docentes.

Portanto, é na escola pública, entendida como escola da maioria, que vivemos a radicalidade de contextos desiguais que brotam do sistema social. A 
ENSINO DE SOCIOLOGIA E EDUCAÇÃO POPULAR: PROBLEMATIZANDO A ESCOLA PÚBLICA

Thiago Ingrassia Pereira

presença curricular da sociologia na atualidade foi precedida de mobilização e luta, acenando para o fortalecimento da consciência crítica e da consequente substantiva prática cidadã esperada.

Exercer a nossa "do-discência" de sociologia na escola pública é construir um espaço emancipatório pautado por uma relação entre sujeitos, jamais entre sujeitos e objetos. Assim, nosso papel político e pedagógico poderá caminhar para o atendimento dos documentos normativos (Diretrizes, Parâmetros e Orientações Curriculares Nacionais), bem como para a construção de um projeto de escola e sociedade transformador. Nesse sentido, passo a refletir sobre a escola pública e o desafio de sua construção como um espaço "popular" a partir da prática pedagógica em sociologia.

\section{A SOCIOLOGIA NA CONSTRUÇÃO DA ESCOLA PÚBLICA E POPULAR}

O conceito "popular" é uma categoria em disputa no âmbito da teoria social (FIOREZE; MARCON, 2009). Por outro lado, em termos de sua construção no seio dos movimentos sociais, a ideia de popular está associada prioritariamente à classe social. Dessa forma, ao me referir à noção de "popular", estou assumindo uma conotação de classe social que encontra amparo no referencial marxista.

Na perspectiva de Freire, o popular amplia-se a partir do conceito de classe social e encontra na categoria "oprimido" sua expressão, que sinaliza para as clivagens materiais e simbólicas que hierarquizam e desumanizam segmentos sociais submetidos ao capitalismo. Assim, ao considerar o debate sobre o popular, filio-me ao entendimento proveniente da tradição dos estudos e experiências de educação popular desenvolvidos a partir da segunda metade do século XX no Brasil.

A educação popular se constitui como uma estratégia de intervenção política gestada a partir dos movimentos sociais críticos à ordem vigente. É um paradigma que acompanha o movimento da sociedade ${ }^{3}$, penetrando com força no contexto

\footnotetext{
3 "Há unanimidade entre os historiadores da educação popular de que ela se forma no movimento da sociedade. Se temos nomes que servem de referência é porque pessoas se dispuseram e tiveram a habilidade de captar a pedagogia que se realizava nesse movimento. No entanto, enquanto processo,
}

Inter-Legere - Revista de Pós Graduação em Ciências Sociais da UFRN Natal RN, ISSN 1982-1662 no 18, jan./jun. de 2016 p. 133-149 
INTER-LEGERE

ENSINO DE SOCIOLOGIA E EDUCAÇÃO POPULAR: PROBLEMATIZANDO A ESCOLA

PÚBLICA

Thiago Ingrassia Pereira

brasileiro das décadas de 1950 e $1960^{4}$, a partir da obra de muitos militantes e ativistas, dentre os quais, Paulo Freire (PALUDO, 2001; BEISIEGEL, 2008; RODRIGUES, 2008).

Ao longo da segunda metade do século $X X$, muitas experiências ligadas à concepção de educação popular se desenvolveram no Brasil. Essa diversidade de movimentos sob essa denominação não nos permite conceituar de forma precisa o que seja educação popular. Contudo, o exame histórico desse campo nos direciona para pelo menos três movimentos que se entrecruzam desde o começo do século $\mathrm{XX}$ :

em primeiro lugar, os trabalhos de educação escolar e práticas de formação de quadros entre os operários. Em segundo lugar, o movimento de educadores e intelectuais pela escola pública e pela democratização derivada da educação. Em terceiro lugar, os movimentos e campanhas de alfabetização de adultos (FLEURI, 2002, p. 55).

Esses movimentos são desdobramentos de duas vertentes que disputam a orientação de projetos no campo da educação popular (ZITKOSKI, 2000). Uma primeira vertente encontra-se voltada para o mundo da economia e do conhecimento instrumental, preparando segmentos das classes populares para o trabalho (sentido profissionalizante), apostando em processos de mobilidade social dentro da sociedade capitalista. Uma segunda compreende a educação como movimento popular, ou seja, centra-se na cultura popular como princípio estratégico para a transformação social.

ela é maior que cada um desses nomes e continua sendo recriada nesse movimento da sociedade" (STRECK, 2010, p. 300).

4 "O encontro com Paulo Freire e outros intelectuais orgânicos nas décadas de 1950 e 1960 complementa um quadro de fundamentação teórica e prática. Nesse encontro, os movimentos populares ganham uma sistematização e identidade de classe que ainda se encontrava difusa" (RODRIGUES, 2008, p. 33). Também, "a história da educação popular geralmente é contada a partir da década de 1960, que no Brasil coincide com uma forte mobilização popular na qual se encontrava inserida a educação, em especial a alfabetização de adultos. A referência mais marcante desse movimento pedagógico-político-cultural é o projeto de Paulo Freire em Angicos, no Rio Grande do Norte, em 1963. Dentre os movimentos implantados no Nordeste, todos no início da década de 1960, podem ser citados o Movimento de Cultura Popular (MCP), criado na Prefeitura de Recife; a campanha 'De pé no chão também se aprende a ler', instituída pela Prefeitura de Natal; e o Movimento de Educação de Base (MEB), criado pela Conferência Nacional dos Bispos do Brasil em convênio com o governo federal" (STRECK, 2010, p. 301).

Inter-Legere - Revista de Pós Graduação em Ciências Sociais da UFRN

Natal RN, ISSN 1982-1662 no 18, jan./jun. de 2016 p. 133-149 
ENSINO DE SOCIOLOGIA E EDUCAÇÃO POPULAR: PROBLEMATIZANDO A ESCOLA PÚBLICA

Thiago Ingrassia Pereira

Seja numa dimensão mais reformista, seja numa perspectiva mais revolucionária, entendo que essas duas vertentes da educação popular nos ajudam a pensar sobre o nosso papel como educadores, apostando em ações politicamente situadas em um projeto de transformação social.

Dessa forma, é possível termos como estratégia política a busca pela emancipação das classes populares a partir de uma educação como prática da liberdade, na qual o desvelamento da realidade se apresenta como possibilidade de mudança. Essa estratégia não nos afasta de posições táticas dentro do sistema hegemônico, justificando, assim, movimentos de disputa por espaços institucionais do aparelho estatal, como é a escola pública.

Nesse sentido, ao projetar uma escola pública e popular, admito o entendimento proveniente do campo da educação popular e me comprometo com a educação dos trabalhadores e trabalhadoras. Nessa direção, assumimos que temos um lado, que não somos apenas "técnicos" ou "burocratas" de práticas pedagógicas, como se fosse possível se assentar em um viés crítico sem perguntar para quem e contra quem trabalhamos. Não é exatamente o propósito do ensino de sociologia permitir aos estudantes questionar a realidade social?

Dessa forma, considero a escola pública um lugar de "resistência", não de assistencialismo. É importante não confundirmos as ideias: o argumento pedagógico que entende a sociedade de classes e suas clivagens, com a correspondente influência no sistema escolar, procura problematizar a lógica individualista e meroticrática. Com isso, não pretendo assumir uma postura de "vitimização" ou "coitadismo" em relação ao estudante de classe popular. Se assim fosse, não teria nada de emancipatória essa perspectiva educacional.

Ao mesmo tempo, criar uma pretensa igualdade no tratamento pedagógico é imaginar que a escola seja refratária aos condicionantes sociais que a formam. À tensão entre "adaptação" e "transformação" adiciona-se outro componente: qual o sentido da escola para as classes populares? Estudos do campo da educação popular sempre demonstraram preocupação com esse aspecto, sinalizando para o debate curricular sobre o que ensinar e aprender (conteúdo) e como proceder nessa tarefa (métodos de ensino). 
ENSINO DE SOCIOLOGIA E EDUCAÇÃO POPULAR: PROBLEMATIZANDO A ESCOLA PÚBLICA

Thiago Ingrassia Pereira

Além disso, com o processo de expansão das matrículas escolares verificado desde a segunda metade do século XX no Brasil, passamos a ter um sistema compelido a fazer mais com menos, ou seja, sem o adequado financiamento do sistema educacional, passamos a ter o desafio de incluir na escola pública um contingente expressivo de estudantes. Esse cenário apresentou desdobramentos pedagógicos em relação ao currículo, pois

a chegada massiva das classes populares à escola, com ampliação de seu tempo de escolarização, incrementa a visibilidade da diferença em seu cotidiano e sua relação com a produção escolar e social da desigualdade, em especial quando se espera que se ajustem ao modelo existente e não que atuem coletivamente na reelaboração do projeto de escolarização vigente. No cotidiano escolar se encontram inúmeras dificuldades para um trabalho pedagógico de qualidade, especialmente quando queremos que a escolarização seja uma experiência importante para as classes populares (ESTEBAN; TAVARES, 2013, p. 297).

Mesmo dentro dos limites do sistema do capital em sua "lógica incorrigível" (MÉSZÁROS, 2005), que deixa o projeto da escola pública e popular permanentemente inconcluso, a ideia de transformá-la como espaço de resistência assume posição central. Nessa direção,

[...] destacamos a categoria de resistência como sendo a chave de leitura para um "novo processo pedagógico", para a construção da nova escola. A resistência "dos de baixo", daqueles que sempre tiveram o mínimo ou quase nada para viver. A resistência a um sistema que os inclui deixando-os de fora, inclusive da escola, porque o que está em disputa é a lógica que gesta a sociedade e, consequentemente, a escola (PALUDO; MACHADO; SILVA, 2012, p. 124).

Com base nesse debate, situo a compreensão das potencialidades do ensino de sociologia na educação básica para a construção da escola pública e popular. Segundo a legislação vigente, a educação escolar deve vincular-se ao mundo do trabalho e à prática social. Portanto, a presença curricular de uma área do conhecimento como a sociologia permite, pelos seus potenciais conteúdos e 
ENSINO DE SOCIOLOGIA E EDUCAÇÃO POPULAR: PROBLEMATIZANDO A ESCOLA PÚBLICA

Thiago Ingrassia Pereira

discussões, a formação de sujeitos que entendam as circunstâncias que condicionam seu percurso enquanto parte de uma coletividade.

De certa forma, ao terem formação inicial em elementos de antropologia, ciência política e sociologia, os estudantes podem formular melhor sua compreensão sobre aspectos presentes no debate público. Entre vários exemplos e, talvez, fugindo de polêmicas muito atuais, recordo que no ano letivo de 2005 trabalhei com turmas de ensino médio sobre o referendo acerca do estatuto do desarmamento.

Esse tema estava presente na grande mídia e tratava diretamente sobre questões envolvendo um dos fundamentos do moderno contrato social: a proteção da vida. Ao orientar os estudantes sobre o tratamento sociológico dessa temática, busquei provocar a reflexão sobre os argumentos expostos, partindo de suas prénoções e as problematizando por meio de fragmentos de textos dos contratualistas (Hobbes, Rousseau e Locke) e outras estratégias (notícias de jornais, análise do documentário "Tiros em Columbine" (2002), de Michael Moore).

O resultado desse trabalho pedagógico-formativo incluiu debate em grupos com as duas posições em jogo ("sim" ou "não" ao referido estatuto), confecção de cartazes que ficaram expostos nos corredores da escola e debate sobre o resultado do referendo nacional, que apontou para a rejeição por cerca de dois terços dos votantes ao comércio de armas de fogo e munição no país. Devido a possibilidades como essa, a aposta em conteúdos e didáticas que advêm do cotidiano dos estudantes parte do referencial da educação popular, afinal, a escola não pode ser apenas um treinamento (FREIRE, 2008).

Fugindo de fórmulas prontas e de um argumento que seja contraditório à própria base teórica que estou apresentando, considero que as diferentes estratégias didáticas estão situadas em possibilidades concretas, ou seja, mesmo o professor e a professora conscientes e politicamente posicionados não poderão, por si sós, alterar radicalmente cenários adversos como os verificados na atualidade. Por isso, o debate sobre a escola e o projeto de uma escola pública e popular a partir dos princípios da educação popular apresenta-se como um "inédito-viável" (FREIRE, 2008). 
ENSINO DE SOCIOLOGIA E EDUCAÇÃO POPULAR: PROBLEMATIZANDO A ESCOLA PÚBLICA

Thiago Ingrassia Pereira

Dessa forma, consideramos as dificuldades atuais, o sucateamento das redes públicas estatais de ensino, a desvalorização do trabalho docente, as contradições da formação inicial em cursos de licenciatura, entre outros aspectos, mas, sobretudo, apostamos no potencial político e de resistência que as instituições públicas possuem.

A aposta em um projeto político que acene para uma escola com viés popular, nos termos apresentados, não exclui a rigorosidade na formação científica, técnica, artística, filosófica que deve ser ofertada em nossas escolas. O argumento defendido apenas destaca as contradições de classe social presentes na sociedade que penetram e condicionam o trabalho no âmbito das escolas. Para além da categoria de classe, outras perspectivas têm permitido alargar a compreensão do que seja o popular, inclusive, transformando-se em proposta de trabalho pedagógico para o ensino de sociologia. É o caso do debate sobre gênero e homofobia (MARIANO et al., 2012) e sobre racismo (OLIVEIRA, 2014).

Percebo que, muitas vezes, ao contrário do que suscitam as temáticas com viés de classe social, gênero e etnia (raça), o debate educacional opera a partir de uma lógica que individualiza os estudantes e coloca os trabalhadores e trabalhadoras em educação na condição de técnicos de gestão pedagógica, desprezando sua criatividade e desperdiçando sua experiência comunitária. Algumas reformas educacionais nos últimos anos parecem ratificar a separação entre os que pensam e os que executam, ou seja, mesmo reconhecendo as prerrogativas dos gestores públicos, os processos verticalizados, quando simplesmente chegam à escola sem a construção devida, geralmente viram letra morta.

Não é objetivo deste artigo proceder a uma análise substantiva da atual proposta de criação de uma base nacional curricular comum por parte do Ministério da Educação. Contudo, sinalizo uma preocupação de que esse debate, entre outras questões, seja apenas mais um documento legal pouco conhecido pela maioria dos colegas docentes que atuam nas salas de aula em nosso país. O esboço de conteúdos para serem trabalhados nacionalmente é válido e tem envolvido especialistas das mais diversas áreas do conhecimento, além da possibilidade de 
ENSINO DE SOCIOLOGIA E EDUCAÇÃO POPULAR: PROBLEMATIZANDO A ESCOLA PÚBLICA

Thiago Ingrassia Pereira

participação da sociedade por meio eletrônico. Porém, insisto, pela experiência histórica, sem que ocorra um enfrentamento com rigor e decisão política sobre os temas financiamento da educação, condições de trabalho nas escolas e formação e valorização do professorado, essa proposta tende a ser mais uma peça burocrática que deve ser executada nas escolas.

Contudo, é importante disputar esse debate, sugerindo alternativas que dialoguem com a base do professorado e da comunidade acadêmica que está comprometida com a qualificação da escola pública. Inclusive, realizar o debate com a comunidade escolar mais ampla, trazendo a situação aos pais e responsáveis e, principalmente, aos estudantes, é uma aposta no protagonismo desses diferentes atores sociais. Sem isso, o projeto popular acerca da escola pública é inviável.

Ao proporem debates sobre temas coletivos da atualidade, os professores de sociologia podem contribuir com processos de construção de pessoas sofisticadas politicamente, com compreensão da razão de ser dos fenômenos sociais, operando epistemologicamente em relação ao seu cotidiano (FREIRE, 2007). Essa possibilidade de conscientização torna o lugar do ensino de sociologia fundamental para o pleno desenvolvimento dos sujeitos no âmbito da sociedade.

Porém, conscientizar não significa tutelar ou promover o ensino de conteúdos de forma "propagandista", ou seja, aulas de sociologia na educação básica não se confundem com propaganda ideológica dos professores e das professoras. Se isso ocorre, estamos diante de profissionais com duvidoso exercício de sua função, o que, aliás, pode acontecer não apenas com professores da área de ciências sociais, mas também das demais disciplinas.

Esse argumento não invalida o compromisso ético dos(as) docentes e sua autonomia para se filiarem a concepções políticas e, até mesmo, partidárias. $\mathrm{O}$ problema reside em ter posições e escamoteá-las, promovendo uma pseudoneutralidade do(a) profissional da educação. Se os(as) nossos(as) estudantes vão votar na esquerda ou na direita (para alguns, até mesmo a existência dessas posições está sendo questionada na atualidade), não é de responsabilidade imediata do(a) professor(a) de sociologia. Porém, se os(as) 
ENSINO DE SOCIOLOGIA E EDUCAÇÃO POPULAR: PROBLEMATIZANDO A ESCOLA PÚBLICA

Thiago Ingrassia Pereira

estudantes sabem o que significam direita e esquerda no espectro político-partidário é um resultado esperado da disciplina de sociologia na escola.

Nos termos freireanos, ao respeitarem as concepções e ideias que os(as) estudantes construíram em suas interações sociais, partindo delas para a problematização com apoio teórico do campo científico das ciências sociais, os(as) professores(as) de sociologia contribuem para a formação de sujeitos com capacidade não apenas de estranhar e desnaturalizar a realidade social, mas, sobretudo, de intervir nela.

De alguma forma, a construção de quaisquer projetos alternativos passa por essa tomada de consciência dos sujeitos, ainda que, por exemplo, apenas ter aulas de sociologia numa perspectiva antirracista não seja capaz de tornar alguém antirracista, pois nossas decisões são orientadas por valores construídos a partir de múltiplos espaços (grupos sociais primários e secundários, mídia, instituições). Aprendemos com Freire que, "não podendo tudo, a prática educativa pode alguma coisa" (FREIRE, 2003, p. 96), e nessa alguma coisa é que aprendi a apostar como sociólogo-educador.

\section{CONSIDERAÇÕES FINAIS}

As reflexões apresentadas neste artigo provocam a pensar sobre possíveis conexões entre educação popular e ensino de sociologia, tendo por base a escola pública. Ao apostar nessa relação, posicionei a argumentação no projeto de uma escola pública e popular.

Considerei minhas experiências como professor de sociologia na educação básica e meu encontro com a pedagogia de Paulo Freire, situando a educação popular como uma práxis pedagógica importante a partir da segunda metade do século XX na América Latina. Por essa razão, foquei no diálogo com alguns autores e autoras de referência, buscando subsídios analíticos para enfrentar o problema da escola pública e, dentro dela, refletir sobre os limites e possibilidade da prática docente em sociologia. 
ENSINO DE SOCIOLOGIA E EDUCAÇÃO POPULAR: PROBLEMATIZANDO A ESCOLA PÚBLICA

Thiago Ingrassia Pereira

Assumo plenamente a posição política em defesa da presença curricular da disciplina de sociologia, representando a área de ciências sociais, no âmbito da educação básica brasileira. Com isso, estou ciente da importância de qualificar os argumentos e dar visibilidade a temas emergentes e espaços materiais e simbólicos, como é a escola pública, bem como de criarmos e fortalecermos espaços de conexão entre as comunidades escolares e acadêmicas, proposta seminal e compromisso da Associação Brasileira de Ensino de Ciências Sociais (ABECS).

Estamos vivendo o sétimo ano da Lei da obrigatoriedade da sociologia no ensino médio e os desafios continuam inúmeros, tanto no meio escolar como no acadêmico. Nesse âmbito, a luta começa desde a formação inicial de professores em cursos de licenciatura em ciências sociais, passando pelo reconhecimento do estatuto científico das temáticas da sociologia escolar no seio dos programas de pós-graduação da área, chegando até a qualificação dos estágios curriculares supervisionados e a manutenção e fortalecimento do Programa Institucional de Bolsas de Iniciação à Docência (PIBID). No campo escolar, os desafios compreendem a abertura de concursos públicos específicos para licenciados(as) em ciências sociais/sociologia, além de questões de carga horária, conteúdos, metodologias e uso do livros didáticos.

Mesmo diante dessas contradições e desafios, termino com esperança, no sentido freireano, de que a escola, em especial a pública, possa fazer parte de um projeto de país mais justo e solidário. Diante disso, acredito que nós, professores e professoras de sociologia, temos algo a dizer/falar/escrever/fazer.

\section{REFERÊNCIAS}

BEISIEGEL, Celso de Rui. Política e educação popular: a teoria e a prática de Paulo Freire no Brasil. 4. ed. Brasília: Liber Livro, 2008.

BOURDIEU, Pierre; PASSERON, Jean Claude. A reprodução: elementos para uma teoria do sistema de ensino. Petrópolis, RJ: Vozes, 2008.

BRANDÃO, Carlos Rodrigues. O que é educação popular. São Paulo: Brasiliense, 2006. 
ENSINO DE SOCIOLOGIA E EDUCAÇÃO POPULAR: PROBLEMATIZANDO A ESCOLA PÚBLICA

Thiago Ingrassia Pereira

CANÁRIO, Rui. A escola tem futuro? Das promessas às incertezas. Porto Alegre: Artmed, 2006.

ESTEBAN, Maria Teresa; TAVARES, Maria Tereza Goudard. Educação popular e a escola pública: antigas questões e novos horizontes. In: STRECK, Danilo Romeu; ESTEBAN, Maria Teresa (Org.). Educação Popular: lugar de construção coletiva. Petrópolis, RJ: Vozes, 2013. p. 293-323.

FERNANDES, Florestan. 0 desafio educacional. São Paulo: Cortez/Autores Associados, 1989.

FERNANDES, Florestan. Educação e sociedade no Brasil. São Paulo: Dominus, 1966.

FLEURI, Reinaldo Matias. A questão do conhecimento na educação popular: uma avaliação do Seminário Permanente de Educação Popular e de suas implicações epistemológicas. ljuí: Editora de Unijuí, 2002.

FREIRE, Paulo. Pedagogia da esperança: um reencontro com a Pedagogia do Oprimido. 15. ed. Rio de Janeiro: Paz e Terra, 2008.

FREIRE, Paulo. Professora sim, tia não: cartas a quem ousa ensinar. 18. ed. São Paulo: Olho d'Água, 2007.

FREIRE, Paulo. Pedagogia da autonomia: saberes necessários à prática educativa. 31. ed. São Paulo: Paz e Terra, 2005.

FREIRE, Paulo. Política e educação. 7. ed. São Paulo: Cortez, 2003.

FREIRE, Paulo. Cartas a Cristina. Rio de Janeiro: Paz e Terra, 1994.

FIOREZE, Cristina; MARCON, Telmo (Org.). O popular e a educação: movimentos sociais, políticas públicas e desenvolvimento. ljuí: Editora da Unijuí, 2009.

GARCIA, Regina Leite. Para quem investigamos - para quem escrevemos: reflexões sobre a responsabilidade social do pesquisador. In: GARCIA, Regina Leite (Org.).

Para quem pesquisamos, para quem escrevemos: 0 impasse dos intelectuais. 3. ed. São Paulo: Cortez, 2011. p. 15-41.

LIBÂNEO, José Carlos. O dualismo perverso da escola pública brasileira: escola do conhecimento para os ricos, escola do acolhimento social para os pobres.

Educação e Pesquisa, São Paulo, v. 38, n. 1, p. 13-28, 2012. 
ENSINO DE SOCIOLOGIA E EDUCAÇÃO POPULAR: PROBLEMATIZANDO A ESCOLA PÚBLICA

Thiago Ingrassia Pereira

MARIANO, Silvana Aparecida et al. Conceituando gênero, conjunturas familiares e homofobia para uso da sociologia no ensino médio. Ensino de sociologia em debate, Londrina, Edição n. 1, v. 1, p. 1-21, jan.-jun. 2012.

MÉSZÁROS, István. A educação para além do capital. São Paulo: Boitempo, 2005.

OLIVEIRA, Luiz Fernandes de. Educação antirracista: tensões e desafios para o ensino de sociologia. Educação \& Realidade, Porto Alegre, v. 39, n. 1, p. 81-98, jan./mar. 2014.

PALUDO, Conceição; MACHADO, Rita de Cássia; SILVA, Andréa Wahlbrink Padilha da. Construção da escola pública e popular como processo de resistência. In: GONÇALVES, Leonardo Dorneles; MACHADO, Carlos RS (Org.). Marx e a educação: trabalho, natureza e conflitos. Porto Alegre: Evangraf, 2012. p. 114-130.

PALUDO, Conceição. Educação popular em busca de alternativas: uma leitura desde o campo democrático e popular. Porto Alegre: Tomo Editorial/Camp, 2001.

PEREIRA, Thiago Ingrassia. Para além do senso comum: aportes para a construção do conhecimento sociológico na educação básica. In: OLIVEIRA, Dijaci David de; RABELO, Danilo; FREITAS, Revalino Antonio de (Org.). Sociologia no ensino médio: experiências e desafios. Goiânia: UFG/FUNAPE, 2010. p. 59-82.

RODRIGUES, Antonio Carlos. Educação popular: histórico e concepções teóricas. In: MELLO, Marco (Org.). Paulo Freire e a educação popular. Porto Alegre: IPPOA/ATEMPA, 2008. p. 31-60.

SOUZA, Rosa Fátima de. História da organização do trabalho escolar e do currículo no século XX: ensino primário e secundário no Brasil. São Paulo: Cortez, 2008.

STRECK, Danilo Romeu. Entre emancipação e regulação: (des)encontros entre educação popular e movimentos sociais. Revista Brasileira de Educação. Rio de Janeiro, v. 15, n. 44, p. 300-310, maio/ago. 2010.

VALLE, Ione Ribeiro, Sociologia da educação: currículo e saberes escolares. 2. ed. Florianópolis: Editora da UFSC, 2014.

ZITKOSKI, Jaime José. Horizontes de (re)fundamentação em educação popular: uma proposta com base na razão dialógica de Freire e na razão comunicativa de Habermas. Frederico Westphalen: Editora da URI, 2000. 